\title{
A Case Study on Condenser Water Supply Temperature Optimization with a District Cooling Plant
}

\author{
Kathryn Hinkelman ${ }^{1}$ Jing Wang ${ }^{1,2}$ Chengliang Fan ${ }^{1,3}$ Wangda Zuo ${ }^{1,2}$ Antoine Gautier ${ }^{4}$ \\ Michael Wetter ${ }^{4}$ Nicholas Long ${ }^{2}$ \\ ${ }^{1}$ Department of Civil, Environmental and Architectural Engineering, University of Colorado Boulder, USA, \\ \{kathryn.hinkelman, jing.wang, chengliang.fan, wangda.zuo\} @colorado.edu \\ ${ }^{2}$ National Renewable Energy Laboratory, USA, nicholas. long@nrel.gov \\ ${ }^{3}$ School of Civil Engineering, Guangzhou University, China \\ ${ }^{4}$ Lawrence Berkeley National Laboratory, USA, \{agautier, mwetter @ lbl .gov
}

\begin{abstract}
District cooling (DC) continues to proliferate due to increasing global cooling demands and economies of scale benefits; however, most district-scale modeling has focused on heating, and to the best of our knowledge, researchers have yet to model cooling plants featuring waterside economizers in DC settings. With the Modelica Buildings library expanding its capabilities to district scale, this study is one of the first to demonstrate how the open-source models can be used for detailed energy and control analysis of a DC plant. For a real-world case study, we developed and validated high-fidelity models for a DC central plant at a college campus in Colorado, USA, and we optimized the condenser water supply temperature (CWST) setpoint across multiple time horizons using the Optimization library in Dymola. Results indicate that annual CWST optimization saves $4.7 \%$ annual plant energy, with less than $1 \%$ of additional energy savings gained through daily optimization. This confirms previous studies' findings that high frequency CWST optimizations are not necessary for the studied system.
\end{abstract}

Keywords: District Cooling, Optimization, Chiller Plant, Waterside Economizer, Modelica Buildings Library

\section{Introduction}

District cooling (DC) systems typically provide cooling services to buildings from central plants and are increasing in demand. In the United States for example, DC serves 174 million square meters of floor space, delivering $15 \mathrm{GW}$ of chilled water annually (ICF LLC and International District Energy Association 2018). This is currently more than any other country, but global installations are growing rapidly, particularly in the Middle East (Marafeq Qatar 2015). With buildings consuming 36\% of global energy (International Energy Agency 2019) and space cooling growing faster than any other end use (International Energy Agency 2018), many are looking to DC for its energy efficiency and economic benefits (Anderson, Rezaie, and Rosen 2021; Oppelt et al. 2016; Zabala et al. 2020). Rather than individual buildings producing their cooling needs with individual air conditioning equipment, centralized plants produce chilled water (CHW) that can be distributed to multiple buildings connected to the district. This aggregation of cooling equipment to a district scale enables the centralized maintenance, the use of more efficient chillers, and the integration of renewable energy resources.

Current modeling and simulation work tends to focus on district heating (DH) with limited focus on DC. A simple Scopus search involving the keywords "model" and either "district heating" or "district cooling" produces 20,109 and 1,230 results, respectively. While some DH research can be applied to DC - as suggested in some DH case studies (del Hoyo Arce et al. 2018; Falay et al. 2020; van der Heijde et al. 2017) - there are also important differences that make DC modeling unique. For example, cooling generation efficiency has heightened sensitivity to even small changes in CHW temperature (e.g., $0.1 K)(\mathrm{Op}-$ pelt et al. 2016), and "low delta-T syndrome" (ASHRAE 2013) is a common energy efficiency problem among DC systems and chiller plants.

Several groups have made valuable contributions to DC modeling literature. High-fidelity and reduced-order modeling techniques have been adapted to reduce plant energy consumption (Chow et al. 2004), peak loads (Gang et al. 2015), and implement model predictive control (Zabala et al. 2020; Matsouka and Hill 2020), to name a few. While a variety of chiller types have been studied - including compressor, absorption, turbo, and double-effect varieties - to the authors' best knowledge, none of the previous literature modeled chiller plants with waterside economizers (WSEs) in DC applications. Further, we only found one study that used Modelica for DC plant modeling (Zabala et al. 2020); yet Modelica is a promising platform for these applications due to its acausal modeling scheme, multitude of variable time-step numerical solvers, and rich open-source libraries with high re-usability potential. This work demonstrates how the popular, open-source Modelica Buildings library can be applied for detailed modeling of chiller plants with WSE for DC applications.

The university wants to identify energy efficiency im- 
provements with little to no financial investments in equipment upgrade. Thus, condenser water supply temperature (CWST) optimization was selected for its past successes in reducing chiller plant energy consumption (Lan Wang, Lee, and Yuen 2018). The condenser water supply is the water entering the condenser of the chillers, and its temperature setpoint affects the chillers' operating efficiency, the economizing heat exchanger's effectiveness, and the required cooling tower fan power. Several past works in chiller plant simulation include CWST optimization (Karami and Liping Wang 2018; Ling et al. 2018), and several optimization time horizons from hourly to monthly have been studied (Huang, Zuo, and Sohn 2017).

In this work, we modeled the DC plant for an existing college campus featuring six connected buildings in Colorado, United States (ASHRAE Climate Zone 5B). The objectives of this case study are to (1) demonstrate the application of Modelica and the Buildings library for detailed energy analysis of a DC plant with a WSE, and (2) identify the the optimal CWST setpoint by evaluating several optimization time horizons. While we selected CWST optimization for this case study, it is important to note that the model can be used for other analyses as well, such as replacing the chillers or adding thermal storage. In Section 2, we present the mechanical and control systems for the case study DC plant. This is followed by the Modelica implementation in Section 3, and the verification and validation of equipment and system models in Section 4. Presentation of the optimization methodology and the optimization results are in Sections 5 and 6. Section 7 concludes the paper with future work.

\section{System Description}

The case study site is a college campus in Colorado's Denver Metropolitan area with a central plant providing chilled water for space and process cooling to six buildings. This section presents the mechanical and control systems for the DC plant.

\subsection{Mechanical System}

As depicted in Figure 1, the cooling plant is a primaryonly chilled water system with parallel connections between a WSE and two chillers on both the plant side (the condenser water (CW) piping) and the load side (the CHW piping). Following standard nomenclature, the condenser water supply (CWS) is the plant-side water being supplied to the chillers, and the return (CWR) is returning to the cooling towers. Similarly, the chilled water supply (CHWS) is being supplied to the district, while the return (CHWR) is returning to the plant. Both the $\mathrm{CW}$ and $\mathrm{CHW}$ loops contain bypasses. The CW bypass valve is a twoposition directional valve to switch between cooling tower and bypass modes, while the CHW bypass valve modulates to maintain the minimum $\mathrm{CHW}$ flow rate through the evaporator of the chillers. Although both the $\mathrm{CW}$ and CHW pumps are equipped with variable frequency drive (VFD) motor controllers, the $\mathrm{CW}$ pumps modulate their

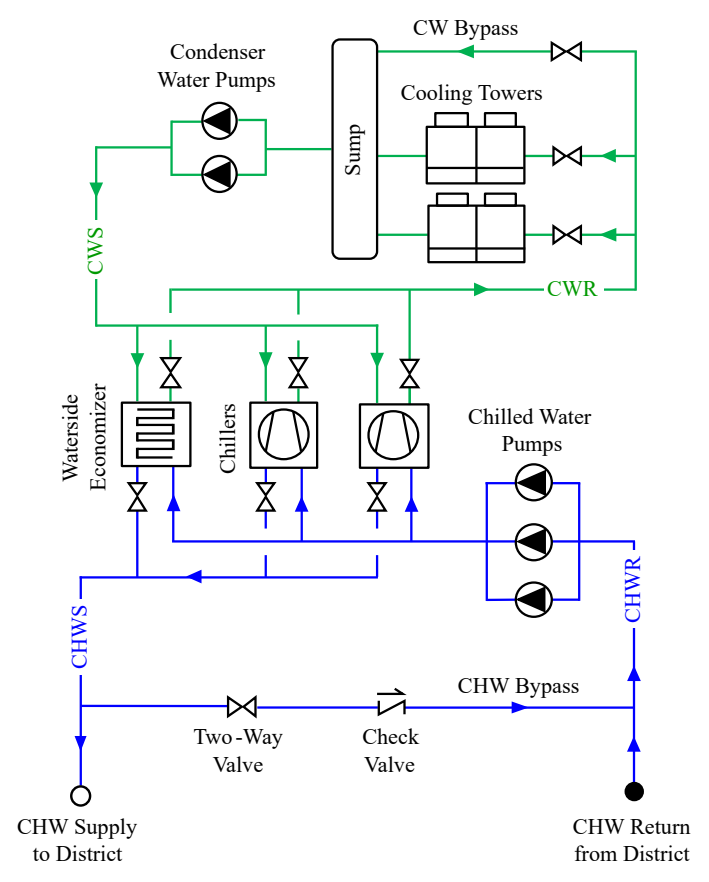

Figure 1. Schematic diagram for the central plant.

speed to maintain a constant flow rate setpoint, while the primary-only CHW pumps operate at variable speeds to maintain a differential pressure setpoint at a distant building. Further details regarding the nominal equipment information can be found in the Appendix (Table 3).

\subsection{Control System}

The control system includes four levels (Figure 2): a toplevel Master Control, Systems Control, Units, and Devices. First, the Master Control determines the operating state of the entire plant and sequences the various "systems". Second, the Systems Control represents the collection of similar "units" physically connected in the process loop. This control level determines correct number of units that should be running to meet the demand (e.g., staging of various equipment). Third, Units represent the collection of devices that combine to perform a specific task. The Units Control level prescribes the setpoint for equipment operation. Lastly, the Devices layer contains single-input single-output (SISO) systems, providing the fundamental building blocks of the control. These are local control setpoints predominantly met by proportional integral (PI) controllers.

At the top Master Control level, the cooling plant can operate in three active cooling modes in addition to the Off mode: (1) Free Cooling (FC) mode, (2) Mechanical Cooling (MC) mode, and (3) Pre-Mechanical Cooling (Pre-MC) mode. The state graph in Figure 3 depicts the switching conditions to move between each of these states. Switching conditions include the total cooling load $\dot{Q}_{C}$ (calculated from temperature and mass flow sensors at the plant); the wetbulb temperature $W B T$ and its switching setpoint $W B T_{S e t}$; the chilled water mass flow rate $\dot{m}_{C H W}$; 


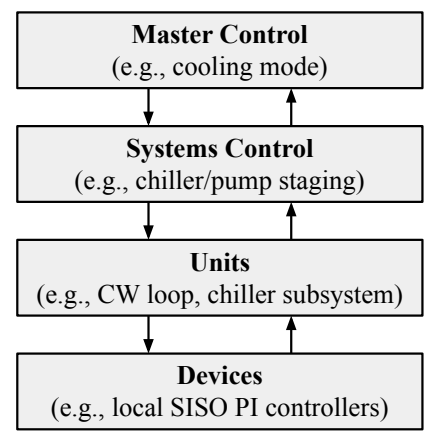

Figure 2. Four control levels of the central plant.

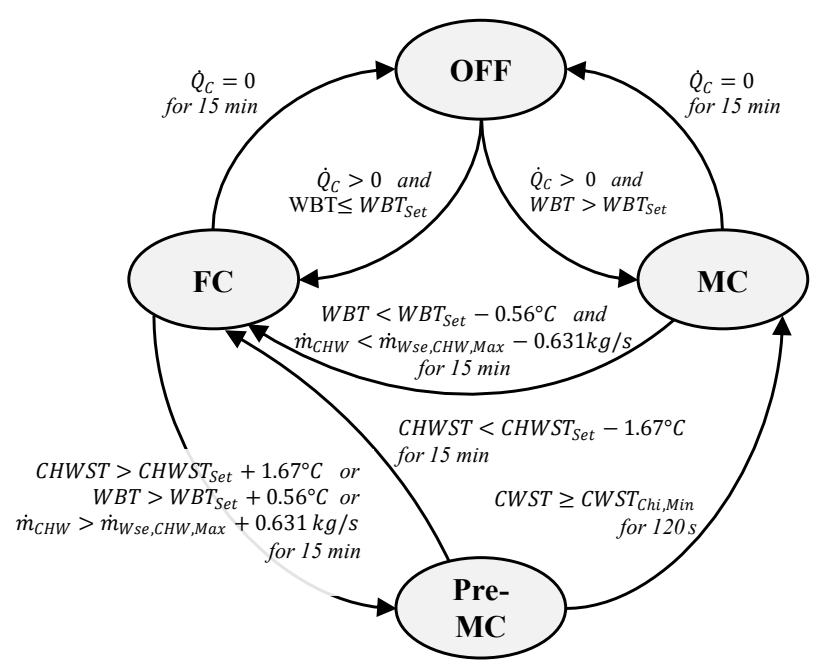

Figure 3. Master control logic for selecting plant cooling mode.

the maximum allowable chilled water mass flow rate for the WSE $\dot{m}_{W s e, C H W, M a x}$; the chilled water supply temperature $C H W S T$ and its setpoint $C H W S T_{S e t}$; the condenser water supply temperature $C W S T$; and the minimum condenser water supply temperature allowed by the chiller $C W S T_{C h i, M i n}$. The offset and dead band temperature of the control signals as well as the waiting times are adjustable. For this plant, the maximum WSE chilled water mass flow rate is $120.5 \mathrm{~kg} / \mathrm{s}$. The wetbulb temperature transition setpoint, the chilled water supply temperature setpoint, and minimum chiller condenser water supply temperature are $6.7^{\circ} \mathrm{C}, 6.1^{\circ} \mathrm{C}$, and $10.0^{\circ} \mathrm{C}$, respectively.

\section{Modelica Implementation}

The DC plant is implemented in Modelica using components from the Modelica Buildings library version 7.0.0 (Wetter et al. 2014) and Modelica Standard Library version 3.2.3. New system and equipment-level models were developed as part of this study, which will be open-source released in the Modelica Buildings library. The system models are presented in a top-down approach in the following sections.

\subsection{Mechanical System}

Shown in Figure 4, the central cooling plant model contains several control blocks on the left with the condenser water (green lines) and chilled water (blue lines) loops on the right. The system's design schematic (Figure 1) and Modelica diagram contain one-to-one modeling relationships, allowing users to clearly interpret the configuration. We connected the inlet and outlet ports of the plant to a district model that reflected the tabulated heat flow rate (broken down by mass flow rate and change in CHW temperature) of the real district from 2018 measured data.

For this case study, the cooling plant features two chillers with a WSE connected in parallel on both the chilled water and condenser water sides. We instantiated the Buildings.Applications.DataCenters.ChillerCooled. Equipment.Nonintegrated model with the optional CHW supply temperature control on the WSE disabled, which implements the ElectricEIR chiller model, based on the DOE-2 electric chiller (Hydeman and Zhou 2007).

New subsystem models for the cooling tower with CW bypass and a parallel cooling tower model were developed based on the Modelica Buildings and Modelica Standard libraries. For the cooling tower model, we instantiated the Merkel model from the Modelica Buildings library, based on the variable speed Merkel model in EnergyPlus version 8.9.0 (United States Department of Energy 2018).

The chilled water pump subsystem was modeled as three parallel speed controlled pumps with inline isolation valves. For the constant speed condenser water pumps, the subsystem included two parallel mass flow controlled pumps. When appropriate, flow controlled pumps (as opposed to speed controlled pumps) typically reduce the size of the nonlinear system of equations in the model, which in turn reduces the simulation run time. However, to note, modelers should use caution when evaluating the energy consumption of ideal pumps that enforce the flow rate regardless of head, because if the pump works against a closed valve, then unrealistic electric power spikes can occur because the power is proportional to the product of the enforced mass flow rate times the pump head, which can be arbitrarily high for this idealized model.

\subsection{Control System}

The four control layers are implemented in Modelica. The Master control (Figure 5) mirrors the schematic state diagram shown previously in Figure 3. Six real inputs decide the state of the Master control mode: Off, FC, MC, or Pre$\mathrm{MC}$. An integer output ranging from 0 to 3 corresponds to the cooling mode status. This control is packaged as one block and instantiated in the top-level system model for the central plant. All Systems control blocks follow a similar implementation.

Figure 6 exemplifies the CW loop control implementation. This includes determining the operating state through the CW control mode staging (Systems level), specifying the temperature setpoint in the CW loop subsystem (Units level), and implementing the local PI controllers for the cooling tower fan and bypass valves (Devices level). Depending on the cooling mode (FC, MC, Pre-MC), either the chilled water or condenser water sup- 


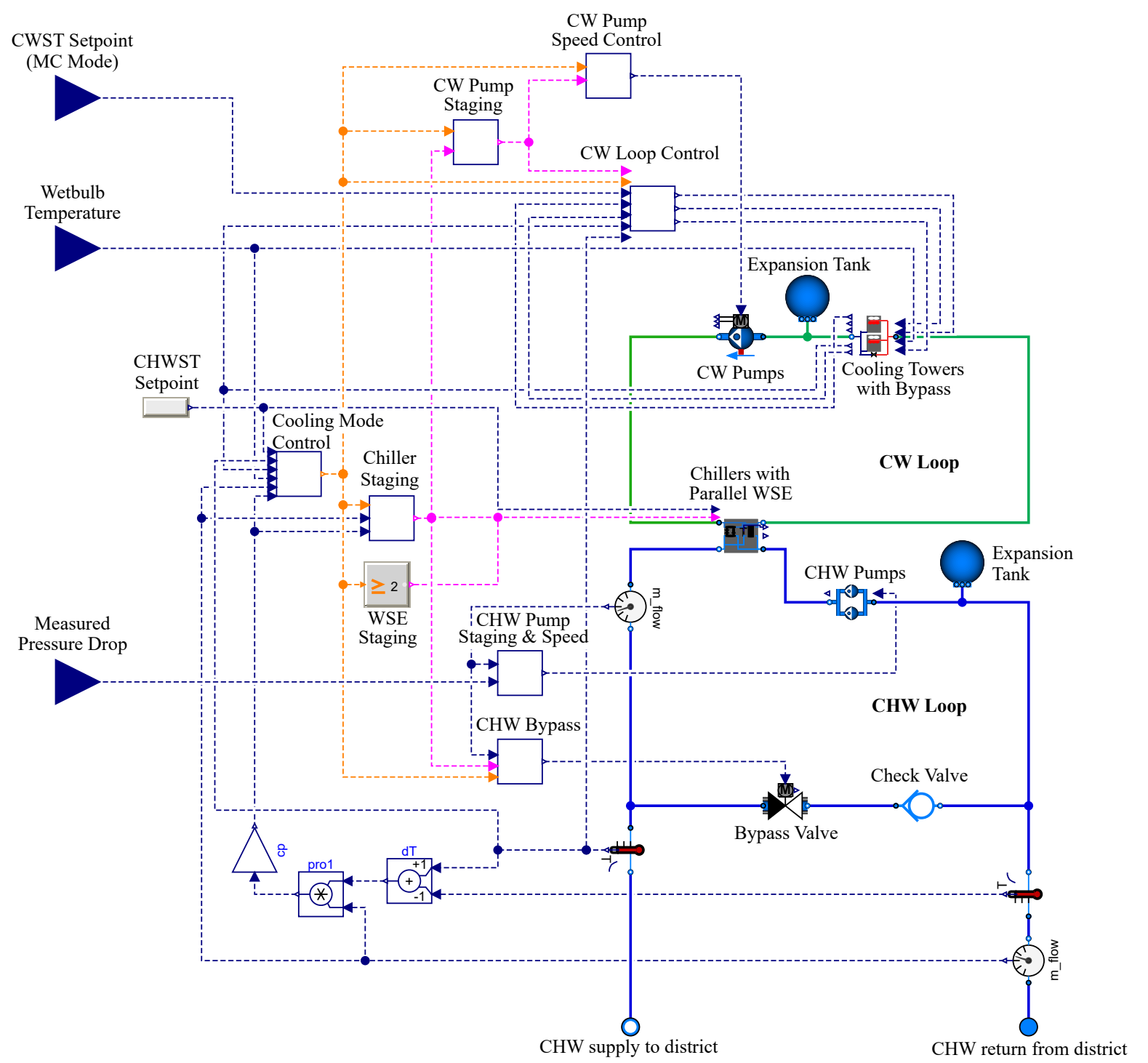

Figure 4. Diagram of Modelica model for the district cooling plant.

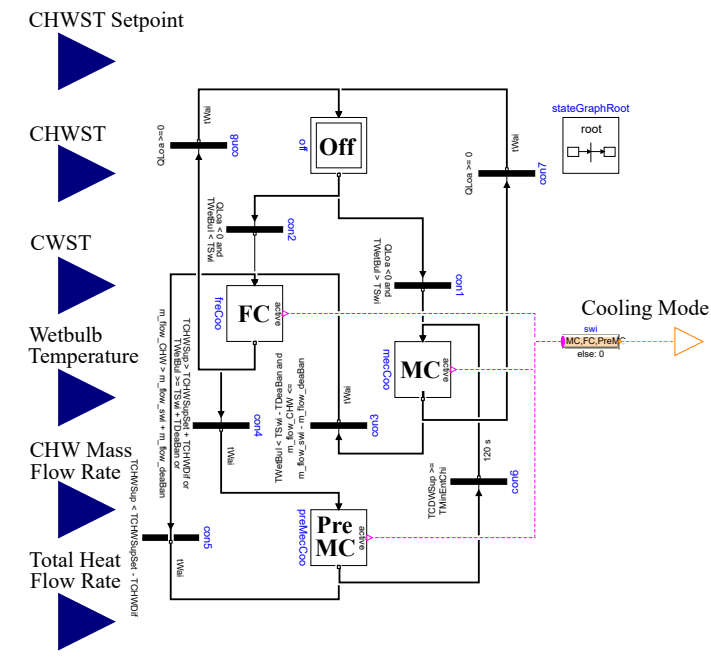

Figure 5. Diagram of the Modelica model for the master control. ply temperature will be controlled. Further, the condenser water supply temperature setpoint changes between $\mathrm{MC}$ and Pre-MC modes. In FC mode, the chilled water supply temperature is controlled. If the measured temperature reading is greater than the setpoint plus the dead band, then the cooling tower fan PI controller is engaged to maintain the setpoint and the CW bypass valve is closed. If the measured temperature reading is less than the setpoint minus the dead band, then the cooling tower fans are off, the CW bypass valve opens, and the cooling tower isolation valves are controlled with the PI controller to maintain the setpoint. This control model is also instantiated on the top system model of the central plant.

Following the control logic of the real system, the three CHW pumps stage on/off based on the campus chilled water flow rate and the pump speeds (Systems level). The CHW pump speeds are modulated to maintain the pressure drop setpoint, with the pressure drop measured at the furthest connected building (Units level). For the two CW pumps, their staging is determined based on the cooling 


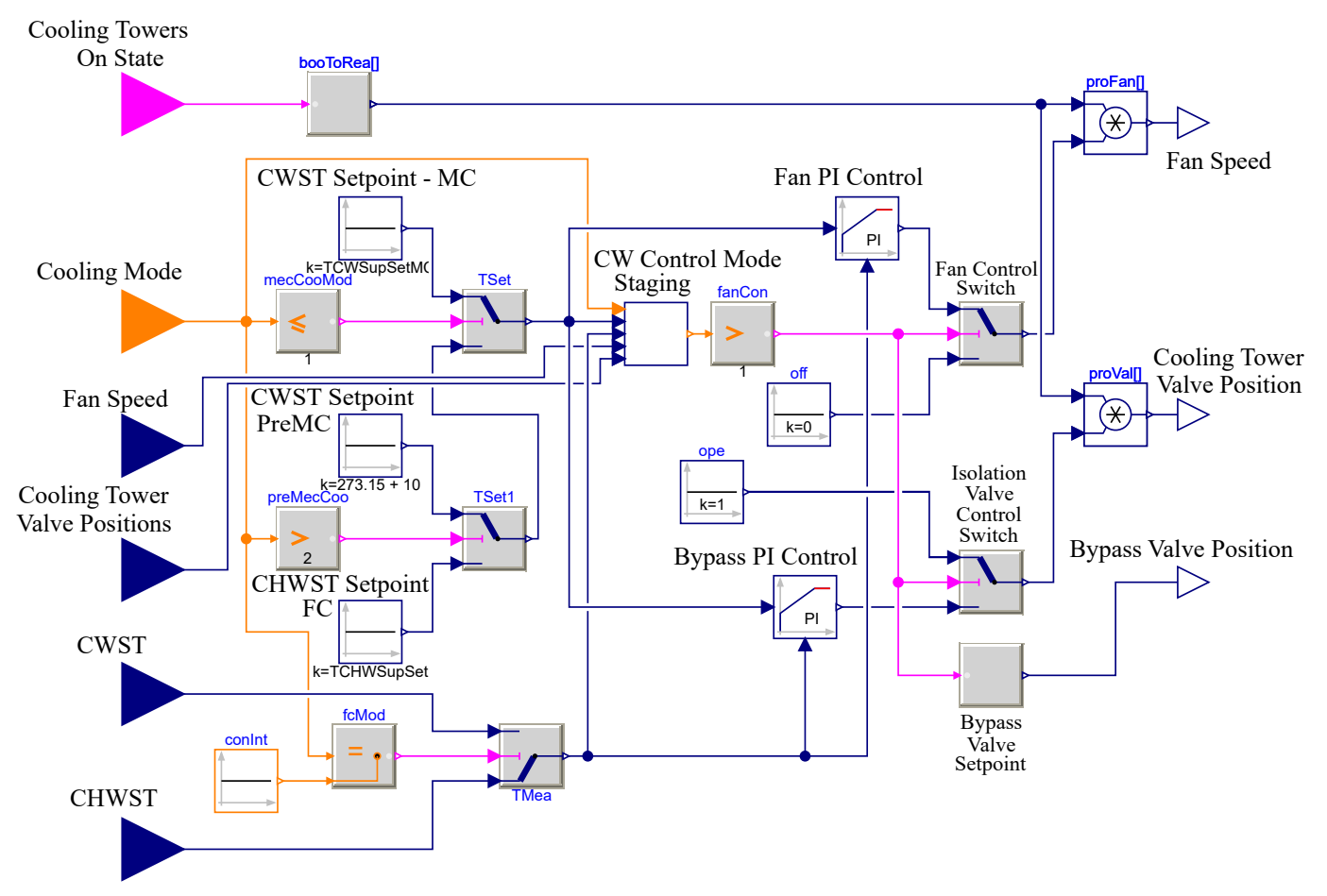

Figure 6. Diagram of the condenser water loop control.

mode and number of chillers running. Their flow rates are controlled at constant setpoints depending on the equipment running ( 1 chiller, 2 chillers, or 1 WSE).

Most Devices control was implemented with SISO PI controllers. For control and numerical stability, the proportional gain $k$ and integral time constant $T i$ were tuned carefully. Consistent with past experiences in dynamic hydraulic models, we found values of $k=0.1$ and $T i=120 \mathrm{~s}$ were effective for most control valve applications. Stable pump and fan control parameters varied across the model.

\subsection{Simulation Settings}

All simulations ran in Dymola 2021 on Linux. While there are many suitable numerical solvers in Dymola for this type of application, CVODE (Hindmarsh, Serban, and Reynolds 2020) was selected for its suitability for solving stiff numerical problems (e.g., the system of differential algebraic equations contain both fast and slow dynamics, which make the selection of a variable time step size difficult for the solver), and in our experience, it typically simulates thermo-fluid systems quickly and robustly. All simulations ran using a tolerance of 1e-6. The computer contained 32 GB of RAM.

\section{Verification and Validation}

To establish an accurate baseline model, we validated major cooling equipment and system-level operation with respect to the measured data. We evaluated the Coefficient of Variation of the Root Mean Square Error (CVRMSE) using hourly time steps as follows:

$$
\text { CVRMSE }=\frac{\sqrt{\frac{\sum\left(y_{i}-\hat{y}_{i}\right)^{2}}{N-1}}}{\bar{y}}
$$

where $y_{i}$ is the individual measured data, $\hat{y}_{i}$ is the corresponding simulation-predicted data, $\bar{y}$ is the mean of the measured dataset, and $N$ is the total number of datapoints.

Due to uncertainties and gaps in measured data, validation of the entire DC plant for one year of measured data was not possible. This is consistent with many past DC and chiller plant modeling endeavors (Oppelt et al. 2016; Fu et al. 2019). Thus, two time periods representing typical summer and winter conditions were selected to validate the model, encompassing both full and part load conditions. With hourly data, the CVRMSE needs to be within $30 \%$ for the model to be considered validated (ASHRAE 2014).

Chilled water heat flow, mass flow, supply temperature, and return temperature were used to validate the model based on the limited availability of historical measurements. Ideally, the pump, chiller, and fan power would be used to validate the model; however, these electrical data points were not available. Thus, we verified equipment and system-level performance with design documents and by consulting plant operators. Historical data was used to the full extent possible to validate the model.

The validation results are summarized in Table 1 . The simulations fell within the $30 \%$ CVRMSE threshold for all locations. During the summer period, the plant operated in mechanical cooling mode with the chiller meeting the cooling demand. While the plant operated in free cooling 
Table 1. Validation results targeting CVRMSE less than $30 \%$.

\begin{tabular}{|c|c|c|c|c|}
\hline \multirow{2}{*}{$\begin{array}{l}\text { Equipment/ } \\
\text { System }\end{array}$} & \multicolumn{4}{|c|}{ CVRMSE (\%) } \\
\hline & $\dot{Q}_{C H W}$ & $\dot{m}_{C H W}$ & $T_{C H W S}$ & $T_{C H W R}$ \\
\hline \multicolumn{5}{|c|}{ Summer Period (Aug. 1-14, 2018) } \\
\hline Plant & 18.8 & 12.9 & 8.9 & 10.3 \\
\hline Chiller & 28.2 & 18.5 & 10.3 & 8.3 \\
\hline \multicolumn{5}{|c|}{ Winter Period (Jan. 28- Feb. 11, 2018) } \\
\hline Plant & 14.6 & 3.1 & 6.2 & 11.3 \\
\hline WSE & 15.6 & 3.1 & 11.3 & 7.1 \\
\hline
\end{tabular}

mode with the WSE meeting the entire cooling demand during the winter period.

Figure 7 visualizes the primary chiller's validation results. Upon inspection, the simulated CHW mass flow rate and supply and return temperatures match the measured data well. However during the nighttime, the measured CHW outlet temperature drifts below the minimum allowable value per the control specifications. Contrarily, the CHW outlet temperature is well controlled at the desired setpoint in the simulation. It is unknown why the real system does not maintain the CHW outlet temperature, and while it is undesirable from a control standpoint, it may be unavoidable due to the real system's transients and extraneous system requirements not included in the model. Based on these validation results, the accuracy of the DC plant model is within acceptable limits of the real system's measured data and expected performance.
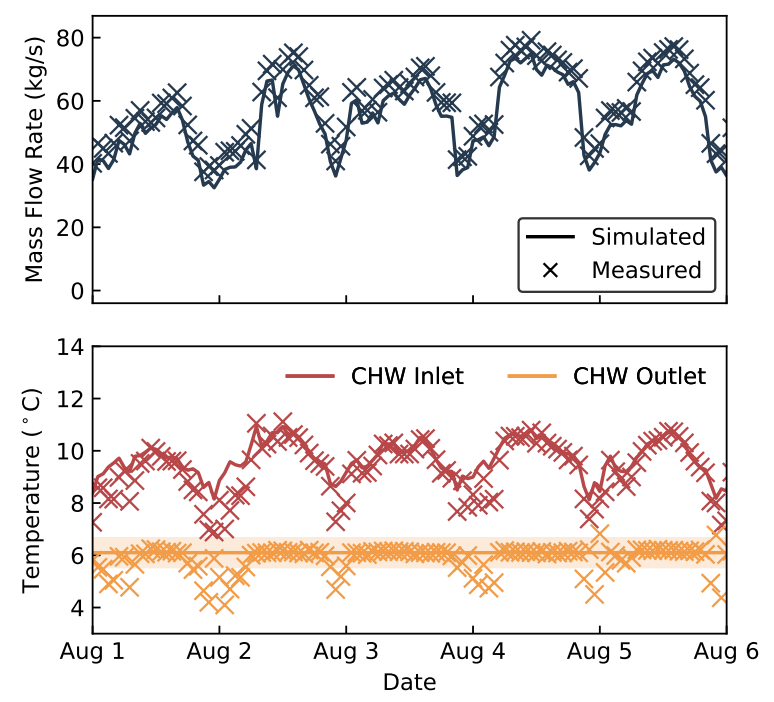

Figure 7. Primary chiller validation results in early August with the highlighted region indicating the control limits for the CHW leaving temperature.

\section{Optimization Problem}

We formulated a sequence of single objective optimization problems that, collectively, minimize the plant's annual energy consumption. The sequence of problems were formulated as follows. Let $\tau=1$ year and $M \in \mathscr{N}$ be the number of intervals over which the optimization problem was solved. Then, we solved the set of problems $\mathbf{P}_{i}$, with

$$
\begin{aligned}
& \mathbf{P}_{i} \min _{x \in\left[\underline{T}_{C W S}, \bar{T}_{C W S}\right]} E_{P l a, i}(x), \\
& E_{P l a, i}(x)=\int_{t_{i}}^{t_{i+1}}\left(P_{C H}(x, s)+P_{C W P}(x, s)\right. \\
& \left.\quad+P_{C H W P}(x, s)+P_{C T}(x, s)\right) d s
\end{aligned}
$$

with $t_{i} \in\left\{t_{i} \in \mathscr{R} \mid t_{i}=i \tau / M, i \in\{0, \ldots, M-1\}\right\}$, where the independent variable $x$ is CWST setpoint, $E_{\text {Pla }, i}$ is the total plant energy during the optimization period $t \in$ $\left[t_{i}, t_{i+1}\right), P_{C H}$ is the power of the chillers, $P_{C W P}$ is the power of the condenser water pumps, $P_{C H W P}$ is the power of the chilled water pumps, $P_{C T}$ is the power of the cooling towers, $\underline{\mathrm{T}}_{C W S}$ is the condenser water supply temperature low limit, and $\bar{T}_{C W S}$ is the condenser water supply temperature high limit. Through this method, the CWST setpoint is selected for each interval (e.g., there are 365 setpoints for a daily optimization case with $M=365$ ).

Based on the chiller's specification documents, the condenser water supply temperature low and high limits are $10.0^{\circ} \mathrm{C}$ and $29.4^{\circ} \mathrm{C}$, respectively. These are used through the optimization process.

Optimization problems with time horizons of one day, week, month, and year are solved using the Optimization library version 2.2.4 (Pfeiffer 2012). Released alongside Dymola 2021, this library allows multi-objective optimization of complex systems within Dymola's modeling and simulation environment. The user interface allows for quick formulation of optimization problems, while the model's state values can be reinitialized for consecutive optimization runs without needing to rerun the entire optimization. For numerical optimization algorithms, we employed the simplex method due to it quicker computational speed as a local method and suitability for handling functions that are not smooth. Optimization and simulation tolerances of 1e-5 and 1e-6 respectively are used for all cases.

\section{Results}

For all cases, the optimized CWST setpoint and energy savings followed similar trends (Figure 8). Due to the limited number of MC hours in winter and fall seasons, the optimized CWST setpoint often stayed at the current setpoint during these times. The optimized CWST setpoint during $\mathrm{MC}$ mode was generally above the current setpoint for all cases.

The CWST optimization reduced the plant's annual energy consumption under all time horizon cases (Table 2), while still meeting the cooling loads at the building end 

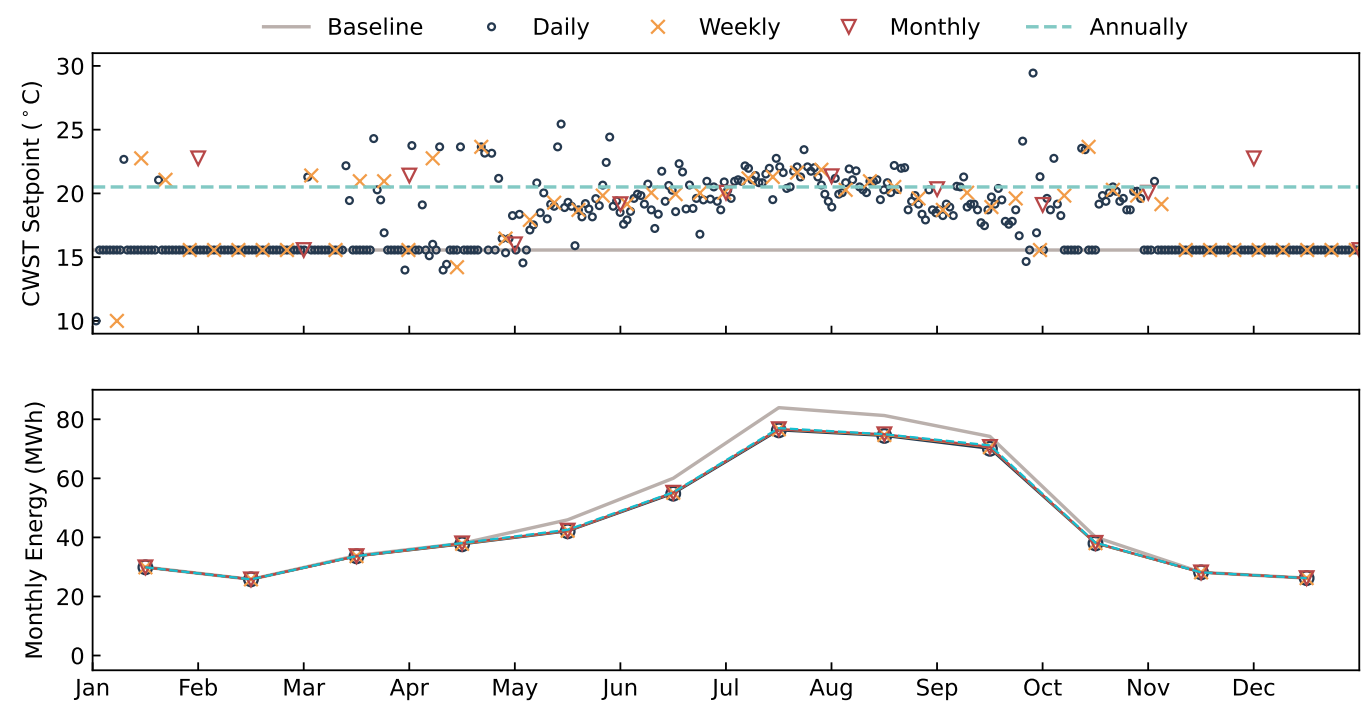

Figure 8. Condenser water supply temperature optimization results across multiple time horizons.

Table 2. Condenser water supply temperature optimization results across multiple time horizons. Energy values represent the plant's annual site energy, and savings are relative to the plant's current implementation (baseline).

\begin{tabular}{|c|c|c|c|c|}
\hline \multirow{2}{*}{$\begin{array}{l}\text { Optimization } \\
\text { Time Horizon }\end{array}$} & \multicolumn{2}{|c|}{$C W S T\left({ }^{\circ} \mathrm{C}\right)$} & \multirow{2}{*}{$\begin{array}{l}\text { Energy } \\
(M W h)\end{array}$} & \multirow{2}{*}{$\begin{array}{r}\text { Saving. } \\
(\%\end{array}$} \\
\hline & Mean & $S D$ & & \\
\hline $\begin{array}{l}\text { No optimization } \\
\text { (baseline) }\end{array}$ & 15.6 & N/A & 567.5 & - \\
\hline Daily & 17.9 & 2.7 & 536.8 & 5.4 \\
\hline Weekly & 18.6 & 2.9 & 538.9 & 5.0 \\
\hline Monthly & 19.5 & 2.6 & 539.6 & 4.9 \\
\hline Annually & 20.5 & N/A & 541.0 & 4.7 \\
\hline
\end{tabular}

users. Annual energy savings were achieved from 4.7\% (annual optimization) to $5.4 \%$ (daily optimization). Because the CWST is controlled in MC mode while the CHWST is controlled in FC mode, the energy savings from CWST optimization occurred during MC mode only. During mechanical cooling, the annual energy savings ranged from $7.4 \%$ with annual optimization to $8.6 \%$ with daily optimization.

\section{Conclusion}

Modeling and simulation of DC systems present ample opportunities for energy-efficient cooling systems at district scales. While Modelica is promising for this application, research in this area is still generally lacking, particularly for central plants featuring free cooling from WSEs. This work aimed to fill this gap by demonstrating how the new models contributed to the open-source Modelica Buildings library can be used for detailed energy analysis and optimization of a DC plant with a WSE connected in parallel with the chillers.

Through CWST optimization cases, around 5\% plant energy was saved with minimal improvements achieved by decreasing the optimization time horizon. This indicates that the seasonal variation on daily through monthly scales does not greatly affect the optimization results, reconfirming the results achieved in previous studies (Huang, Zuo, and Sohn 2017). We recommend that the plant implement the annual CWST optimization because it is a robust and simple control retrofit.

The CWST optimizations exemplify retrofit strategies that are possible with the detailed Modelica models, but are by no means comprehensive. In the future, we plan to pursue additional retrofit strategies with higher energy saving potentials, including integrating the WSE with the chillers, adding thermal storage, and integrating the highfidelity plant model with a complete district model to evaluate co-operational strategies across buildings and the plant.

\section{Acknowledgements}

This work was supported by the Building Technologies Office of the U.S. Department of Energy, under contract numbers DE-AC36-08GO28308 and DE-AC02$05 \mathrm{CH} 11231$. This research was also supported by the National Science Foundation under Award No. IIS-1802017. BIGDATA: Collaborative Research: IA: Big Data Analytics for Optimized Planning of Smart, Sustainable, and Connected Communities. Further, this work emerged from the IBPSA Project 1, an international project conducted under the umbrella of the International Building Performance Simulation Association (IBPSA). Project 1 will develop and demonstrate a BIM/GIS and Modelica Framework for building and community energy system design and operation. The authors would also like to thank the campus facilities team for their assistance with data collection, expert advice, and overall support of this project. 


\section{References}

Anderson, Austin, Behnaz Rezaie, and Marc A. Rosen (2021). "An innovative approach to enhance sustainability of a district cooling system by adjusting cold thermal storage and chiller operation”. In: Energy 214, p. 118949. ISSN: 03605442. DOI: $10.1016 /$ j.energy.2020.118949.

ASHRAE (2013). "District Cooling Guide". In: District Cooling Guide. Atlanta, GA: American Society of Heating, Refrigerating and Air-Conditioning Engineers, Inc. ISBN: 9781936504428.

ASHRAE (2014). ASHRAE Guideline 14-2014: Measurement of Energy, Demand, and Water Savings. Tech. rep. Atlanta, GA.

Chow, Tin Tai et al. (2004). "Energy modelling of district cooling system for new urban development". In: Energy and Buildings 36.11, pp. 1153-1162. ISSN: 03787788. DOI: 10 . 1016/j.enbuild.2004.04.002.

del Hoyo Arce, Itzal et al. (2018). "Models for fast modelling of district heating and cooling networks". In: Renewable and Sustainable Energy Reviews 82.July, pp. 1863-1873. ISSN: 18790690. DOI: 10.1016/j.rser.2017.06.109.

Falay, Basak et al. (2020). "Enabling large-scale dynamic simulations and reducing model complexity of district heating and cooling systems by aggregation". In: Energy 209, p. 118410. ISSN: 03605442. DOI: 10.1016/j.energy.2020.118410.

$\mathrm{Fu}$, Yangyang et al. (2019). "Equation-based object-oriented modeling and simulation for data center cooling: A case study". In: Energy and Buildings 186, pp. 108-125. ISSN: 0378-7788. DOI: 10.1016/j.enbuild.2019.01.018.

Gang, Wenjie et al. (2015). "Performance Assessment of District Cooling System Coupled with Different Energy Technologies in Subtropical Area". In: Energy Procedia 75, pp. 12351241. ISSN: 18766102. DOI: 10.1016/j.egypro.2015.07.166.

Hindmarsh, Alan C, Radu Serban, and Daniel R. Reynolds (2020). User documentation for CVODE v5.1.0 (SUNDIALS v5.1.0). Tech. rep. Lawrence Livermore National Laboratory. URL: https://computing.1lnl.gov/projects/sundials/sundialssoftware.

Huang, Sen, Wangda Zuo, and Michael D. Sohn (2017). "Improved cooling tower control of legacy chiller plants by optimizing the condenser water set point". In: Building and Environment 111, pp. 33-46. ISSN: 03601323. DOI: 10.1016/j. buildenv.2016.10.011.

Hydeman, Mark and Guo Zhou (2007). "Optimizing chilled water plant control”. In: ASHRAE Journal 49.6, pp. 44-54. ISSN: 00012491.

ICF LLC and International District Energy Association (2018). U.S. District Energy Services Market Characterization. Tech. rep. Washington DC: U.S. Energy Information Administration. URL: https://www.eia.gov/analysis/studies/buildings/ districtservices/pdf/districtservices.pdf.

International Energy Agency (2018). The Future of Cooling: Opportunities for energy-efficient air conditioning. Tech. rep., p. 92.

International Energy Agency (2019). 2019 Global Status Report for Buildings and Construction: Towards a zero-emissions, efficient and resilient buildings and construction sector. Tech. rep., pp. 1-48.

Karami, Majid and Liping Wang (2018). "Particle Swarm optimization for control operation of an all-variable speed water-cooled chiller plant". In: Applied Thermal Engineer- ing 130, pp. 962-978. ISSN: 13594311. DOI: $10.1016 / \mathrm{j}$. applthermaleng.2017.11.037.

Ling, Li et al. (2018). "Energy saving analysis of the cooling plant using lake water source base on the optimized control strategy with set points change". In: Applied Thermal Engineering 130, pp. 1440-1449. ISSN: 13594311. DOI: 10.1016/ j.applthermaleng.2017.10.152.

Marafeq Qatar (2015). District Cooling: GCC and Qatar. Tech. rep. April.

Matsouka, Kenichi and David Hill (2020). "Online Optimization of Cooling Water System in a District Cooling Plant by Using Digital Twin”. In: ASHRAE Transactions 126.2, pp. 427-434.

Oppelt, Thomas et al. (2016). "Dynamic thermo-hydraulic model of district cooling networks". In: Applied Thermal Engineering 102, pp. 336-345. ISSN: 13594311. DOI: 10.1016/ j.applthermaleng.2016.03.168.

Pfeiffer, Andreas (2012). "Optimization Library for Interactive Multi-Criteria Optimization Tasks". In: Proceedings of the 9th International Modelica Conference. Vol. 76. Munich, Germany, pp. 669-680. DOI: 10.3384/ecp12076669.

United States Department of Energy (2018). EnergyPlus Version 8.9.0 Documentation: Engineering Reference. Tech. rep., p. 1716. URL: https : / / energyplus . net / sites / all / modules / custom / nrel_ custom / pdfs / pdfs _ v8 .9.0/ EngineeringReference.pdf.

van der Heijde, Bram et al. (2017). "Dynamic equation-based thermo-hydraulic pipe model for district heating and cooling systems". In: Energy Conversion and Management 151, pp. 158-169. DOI: 10.1016/j.enconman.2017.08.072.

Wang, Lan, Eric W.M. Lee, and Richard K.K. Yuen (2018). “A practical approach to chiller plants' optimisation". In: Energy and Buildings 169, pp. 332-343. ISSN: 03787788. DOI: 10. 1016/j.enbuild.2018.03.076.

Wetter, Michael et al. (2014). "Modelica Buildings library". In: Journal of Building Performance Simulation 7.4, pp. 253270. DOI: 10.1080/19401493.2013.765506.

Zabala, Laura et al. (2020). "Virtual testbed for model predictive control development in district cooling systems". In: Renewable and Sustainable Energy Reviews 129. ISSN: 18790690. DOI: 10.1016/j.rser.2020.109920.

\section{Appendix}

See Table 3 for the plant's nominal information. 
Table 3. Nominal information for the central cooling plant equipment.

\begin{tabular}{|c|c|c|c|c|c|}
\hline Equipment & Qty. & Nominal & quipment Information & Unit & Value \\
\hline \multirow{14}{*}{ Chiller } & \multirow{14}{*}{2} & \multicolumn{2}{|c|}{ Nominal Capacity } & $\mathrm{kW}$ & 2450 \\
\hline & & \multirow{2}{*}{ Design Efficiencies } & Coefficient of Performance (COP) & - & 6.80 \\
\hline & & & $\mathrm{kW} / \mathrm{ton}$ & $\mathrm{kW} / \mathrm{ton}$ & 0.517 \\
\hline & & \multirow{4}{*}{ Evaporator } & Flow Rate & $\mathrm{m}^{3} / \mathrm{s}$ & 0.0878 \\
\hline & & & Pressure Loss & $\mathrm{kPa}$ & 29.0 \\
\hline & & & Design Entering Temperature & ${ }^{\circ} \mathrm{C}$ & 12.2 \\
\hline & & & Design Leaving Temperature & ${ }^{\circ} \mathrm{C}$ & 28.4 \\
\hline & & \multirow{4}{*}{ Condenser } & Flow Rate & $\mathrm{m}^{3} / \mathrm{s}$ & 0.133 \\
\hline & & & Pressure Loss & $\mathrm{kPa}$ & 64.6 \\
\hline & & & Design Entering Temperature & ${ }^{\circ} \mathrm{C}$ & 23.3 \\
\hline & & & Design Leaving Temperature & ${ }^{\circ} \mathrm{C}$ & 28.4 \\
\hline & & \multirow{3}{*}{ Compressor } & Number & - & $\overline{1}$ \\
\hline & & & Speed Type & - & Variable \\
\hline & & & Power & $\mathrm{kW}$ & 366 \\
\hline \multirow{6}{*}{$\begin{array}{l}\text { Waterside } \\
\text { Economizer }\end{array}$} & \multirow{6}{*}{1} & \multirow{2}{*}{\multicolumn{2}{|c|}{$\begin{array}{c}\text { Nominal Capacity } \\
\text { Design Approach Temperature }\end{array}$}} & $\mathrm{kW}$ & 2820 \\
\hline & & & & ${ }^{\circ} \mathrm{C}$ & 1.7 \\
\hline & & \multirow{2}{*}{ Chilled Water Side } & Flow Rate & $\mathrm{m}^{3} / \mathrm{s}$ & 0.121 \\
\hline & & & Pressure Loss & $\mathrm{kPa}$ & 48.4 \\
\hline & & \multirow{2}{*}{ Condenser Water Side } & Flow Rate & $\mathrm{m}^{3} / \mathrm{s}$ & 0.151 \\
\hline & & & Pressure Loss & $\mathrm{kPa}$ & 83.1 \\
\hline \multirow{4}{*}{$\begin{array}{l}\text { Chilled } \\
\text { Water Pump }\end{array}$} & \multirow{4}{*}{3} & & Head & $\mathrm{kPa}$ & 252 \\
\hline & & & Power & $\mathrm{kW}$ & 29.8 \\
\hline & & & Flow Rate & $\mathrm{m}^{3} / \mathrm{s}$ & 0.0883 \\
\hline & & & Speed Type & - & Variable \\
\hline \multirow{4}{*}{$\begin{array}{l}\text { Condenser } \\
\text { Water Pump }\end{array}$} & \multirow{4}{*}{2} & & Head & $\mathrm{kPa}$ & 338 \\
\hline & & & Power & $\mathrm{kW}$ & 55.9 \\
\hline & & & Flow Rate & $\mathrm{m}^{3} / \mathrm{s}$ & 0.126 \\
\hline & & & Speed Type & - & Variable \\
\hline \multirow{8}{*}{$\begin{array}{l}\text { Cooling } \\
\text { Tower }\end{array}$} & \multirow{8}{*}{2} & \multicolumn{2}{|c|}{ Nominal Capacity } & $\mathrm{kW}$ & 2813 \\
\hline & & \multirow{2}{*}{\multicolumn{2}{|c|}{$\begin{array}{l}\text { Nominal Flow Rate } \\
\text { Number of Cells }\end{array}$}} & $\mathrm{m}^{3} / \mathrm{s}$ & 0.158 \\
\hline & & & & - & 2 \\
\hline & & \multicolumn{2}{|c|}{ Nominal Fan Power } & $\mathrm{kW}$ & 22.4 \\
\hline & & \multicolumn{2}{|c|}{ Fan Speed Type } & - & Variable \\
\hline & & \multirow{3}{*}{ Design Temperatures } & Hot Water & ${ }^{\circ} \mathrm{C}$ & 28.2 \\
\hline & & & Cold Water & ${ }^{\circ} \mathrm{C}$ & 22.6 \\
\hline & & & Wetbulb & ${ }^{\circ} \mathrm{C}$ & 17.8 \\
\hline
\end{tabular}

